\title{
DISPOSITIVO: UM SOLO PARA A SUBJETIVAÇÃO
}

\author{
Amadeu de Oliveira Weinmann \\ Universidade Federal do Rio Grande do Sul
}

RESUMO: O artigo pretende mostrar a fecundidade do conceito de dispositivo na problematização foucaultiana do sujeito. Nesse sentido, em um primeiro momento analisa o modo como Foucault concebe a constituição histórica de um sujeito em termos de assujeitamento à trama de saberes e poderes de um dispositivo. Em seguida, realça a inflexão ocorrida na referida problematização, a qual leva a pensar a subjetivação como uma prática de liberdade, isto é, como uma experiência-limite operada nas bordas de um dispositivo. Por fim, propõe que cartografar um dispositivo consiste em delinear a agonística da sujeição/subjetivação que atravessa um sujeito.

PALAVRAS-CHAVE: dispositivo; sujeito; assujeitamento; subjetivação; dobra.

\section{DEVICE: EARTH FOR SUBJECTIVATION}

ABSTRACT: The article intends to show the creative power of the concept of device in Foucault's problematization of the subject. In this sense, at first, it analyses the way Foulcault conceives the subject as historically constituted in terms of subjection to the meshwork of knowledge and power of a device. Then, it highlights the inflection that occurs in the referred problematization, which leads to consider subjectivation as a practice of freedom, i.e., as a limit-experience operating in the boundaries of a device. Finally, it proposes that cartographing a device consists in outlining the agonistics of subjection/subjectivation that transverses a subject.

KEYWORDS: device; subject; subjection; subjectivation; fold.

\section{A morte do homem}

Penso ser pertinente afirmar que a problematização do sujeito é um dos temas cruciais da filosofia de Michel Foucault. O próprio Foucault (1995a, p. 7) enuncia assim o seu projeto: "é preciso se livrar do sujeito constituinte, livrar-se do próprio sujeito, isto é, chegar a uma análise que possa dar conta da constituição do sujeito na trama histórica". Essa postura filosófica decorre do pressuposto de que a episteme moderna é inteiramente atravessada por um conceito de sujeito, que é universal em sua substância e constituinte da experiência humana, em sua diversidade histórica. Esse sujeito - o homem: um duplo empírico/ transcendental, condição de possibilidade e, ao mesmo tempo, sujeito e objeto dos saberes das Ciências Humanas -é o elemento ordenador de toda produção discursiva com pretensão de cientificidade, realizada nos marcos desse sistema de pensamento (Foucault, 2002).

Por consistir no impensado dessa episteme, no sistema que rege a formação e a transformação dos seus enunciados (Foucault, 2000), esse sujeito é exatamente o que deve ser problematizado, para que pensar seja possível: "em nossos dias não se pode mais pensar senão no vazio do homem desaparecido" (Foucault, 2002, p. 473). E esse é o motivo pelo qual Foucault adota a problematização do sujeito como projeto filosófico. Como assinala Deleuze (2005, p. 124):

[...] uma coisa perturba Foucault, e é o pensamento. "Que significa pensar? O que se chama pensar?" a pergunta lançada por Heidegger, retomada por Foucault, é a mais importante de suas flechas. Uma his- tória, mas do pensamento enquanto tal. [...] O saber, o poder e o si são a tripla raiz de uma problematização do pensamento.

Analisar um sujeito em sua constituição histórica acarreta algumas considerações metodológicas. De acordo com Foucault (2004a), é crucial adotar uma atitude de ceticismo sistemático em relação a todos os universais antropológicos ${ }^{1}$ encontrados em uma prática discursiva qualquer. No entanto, isso não significa recusá-los, imediatamente, como irreais, ou atribuí-los a interesses obscuros, que visam mascarar ou distorcer a realidade da natureza humana. Suspeitar dos universais antropológicos implica perguntar pelos jogos de verdade que lhes oferecem sustentação, ou seja, "[...] é se interrogar sobre as condições que permitem, conforme as regras do dizer verdadeiro ou falso, reconhecer um sujeito como doente mental ou fazer com que um sujeito reconheça a parte mais essencial dele próprio na modalidade do seu desejo sexual" (Foucault, 2004a, p. 237). E isso por que a constituição de um sujeito se dá na imanência de um corpo de saberes, que o toma como objeto, na forma de um conhecimento legítimo.

Disso decorre um segundo princípio de método. É preciso inverter o procedimento filosófico, característico da episteme moderna, de remontar a um sujeito constituinte a multiplicidade das formas de subjetivação, que proliferam em diferentes circunstâncias históricas. Foucault (2004a) observa ser necessário estudar as práticas concretas, mediante as quais objetiva-se um sujeito, a fim de descrever as formas de racionalidade estratégica que lhes concernem e por meio das quais se delineia, simultaneamente, um 
certo domínio de experiências possíveis e o modo como um sujeito deve fazer a experiência de si próprio neste campo. Afirmar que essas práticas fazem de um sujeito o seu objeto é apontar para além de uma relação epistêmica, que constrói um saber sobre este sujeito. Trata-se de analisar uma operação de assujeitamento que, ao mesmo tempo em que enuncia a verdade de um sujeito, o liga, coercitivamente, a uma determinada identidade. ${ }^{2}$

Nesse sentido, Foucault pesquisou a constituição dos sujeitos modernos, a partir de três modos de objetivação:

- Em práticas epistêmicas, que objetivam um sujeito como um duplo empírico/transcendental - o homem -, erigido, no raiar da Modernidade, como sujeito da razão transcendental, pela filosofia kantiana, e como sujeito que vive, fala e trabalha, pelas ciências empíricas (Biologia, Filologia e Economia Política).

- Em práticas divisoras, mediante as quais os sujeitos são individualizados e distribuídos em torno de um eixo de normalização, em um processo de objetivação de um sujeito como louco ou racional, doente ou saudável, delinqüiente ou honesto, sexualmente normal ou perverso.

- E em práticas de si, por meio das quais um sujeito toma a si próprio como objeto de saber e de poder, de modo a construir a sua experiência de si como um sujeito de desejo.

\section{Saber e poder}

A um determinado agrupamento de práticas, que constituem um sujeito em uma trama de saberes e em um feixe de forças que lhes são imanentes, Foucault (1995c, p. 244) denomina dispositivo, definindo-o como:

[...] um conjunto decididamente heterogêneo que engloba discursos, instituições, organizações arquitetônicas, decisões regulamentares, leis, medidas administrativas, enunciados científicos, proposições filosóficas, morais, filantrópicas. Em suma, o dito e o não dito são os elementos do dispositivo. $O$ dispositivo é a rede que se pode estabelecer entre estes elementos.

De acordo com tal enfoque, pode-se afirmar que o dispositivo educacional moderno consiste em um conjunto heterogêneo de práticas disciplinares (Foucault, 1987), tais como: discursos sobre a importância de educar a infância, instituições educacionais diversas, prédios e regulamentos escolares, leis de ensino, portarias ministeriais, enunciados com pretensão de cientificidade - pedagógicos, psicológicos, sociológicos, etc -, filosofias educacionais, proposições moralizadoras da infância, etc. Ao longo das suas séries - que constituem uma temporalidade linear e evolutiva, cujos momentos integram-se um no outro e se dirigem para um ponto ideal -, esse dispositivo disciplinar não prolonga a infância, como propõe Ariès (1981), mas produz o sujeito infantil, ao mesmo tempo em que estabelece o adulto dito normal - isto é, racional e moral - como a meta do seu processo de assujeitamento (Corazza, 2000).

Um dispositivo também pode ser conceitualizado como uma configuração específica de domínios do saber e de modalidades de exercício do poder, a qual possui uma função estratégica, em relação a problemas considerados cruciais em um momento histórico (Foucault, 1995c). Em seus movimentos estratégicos, um dispositivo intervém de forma racional ${ }^{3}$ sobre o campo de forças em que se insere, com o intuito de desenvolvê-las em determinada direção, de barrar-lhes certos caminhos, de utilizá-las em proveito de seus fins. Entretanto, o fato de essas forças serem móveis, instáveis, heterogêneas e da sua confrontação ser inevitavelmente tensa - pelos efeitos de resistência que suscita -, desequilibrada e de realizar-se em espaço aberto (Foucault, 1997a) torna incerta a estabilidade de um dispositivo, produz a necessidade de rearranjos e de rearticulações constantes em sua configuração e gera fissuras nos estados de dominação que tal dispositivo engendra.

\section{$O$ dispositivo de sexualidade e a constituição de sujeitos desejantes}

Em $A$ vontade de saber, Foucault analisa a constituição do sujeito do desejo nos marcos do moderno dispositivo de sexualidade. Novos domínios do saber aparecem: a Psiquiatria, a Criminologia, a Pedagogia, a Demografia, etc. Uma nova tecnologia política, orientada para a gestão da vida e, simultaneamente, individualizante (disciplina dos corpos) e totalizadora (regulação das populações) consolida-se: o bio-poder. Na intersecção entre esses campos do saber e essas formas de exercício do poder, o dispositivo de sexualidade constrói o sexo como objeto da nascente scientia sexualis e promove um rigoroso esquadrinhamento das práticas sexuais. De acordo com Foucault, em um mesmo movimento esse dispositivo disciplina os corpos e regula as populações, estabelece um regime de prazeres e ocupa-se da preservação da espécie.

Erigindo o desejo como o mais recôndito segredo dos sujeitos modernos - o seu mais precioso e perigoso dote, lugar da sua verdade e chave da sua liberdade -, o dispositivo de sexualidade amplia o espectro das práticas sexuais reconhecidas e relança, de uma forma muito mais sofisticada, a identificação de um sujeito à verdade do seu sexo. No cerne desse processo, uma técnica - a confissão: "por confissão entendo todos estes procedimentos pelos quais se incita o sujeito a produzir sobre sua sexualidade um discurso de verdade que é capaz de ter efeitos sobre o próprio sujeito" (Foucault, 1995c, p. 264). Foucault sugere que a injunção a que um sujeito produza uma verdade a respeito de si próprio, fixando-se uma identidade a partir das formas que reconhece em seu desejo, remonta à orga- 
nização da doutrina e da pastoral cristã da carne. O dispositivo de sexualidade extrai da tecnologia da carne a técnica da confissão, reinserindo-a em uma nova rede de relações.

Porém, após a publicação do primeiro volume da História da sexualidade, Foucault desloca o foco da análise. Importa-lhe, agora, pesquisar as modalidades de relação consigo, mediante as quais os sujeitos modernos constroem a experiência de si próprios como sujeitos de uma sexualidade. Para descrever esse modo de subjetivação, Foucault re-orienta o seu projeto genealógico, no sentido de investigar as práticas de si, por meio das quais o homem ocidental, ao longo de muitos séculos, foi levado a se reconhecer como sujeito de desejo. Foucault (2001, p. 10) atribui a alteração dos balizamentos cronológicos dessa genealogia - que o remeteu a estudar a lenta formação, desde a Antigüidade, de uma hermenêutica do desejo - ao fato de que "a experiência da sexualidade pode muito bem se distinguir, como figura histórica singular, da experiência cristã da 'carne': mas elas parecem ambas dominadas pelo princípio do "homem do desejo".

Essa modificação no plano de pesquisa resulta de uma inflexão importante na problematização foucaultiana do sujeito. Em entrevista com Foucault, François Ewald assinala essa ruptura:

As obras precedentes deram do senhor uma imagem de pensador do aprisionamento, dos sujeitos submetidos, coagidos e disciplinados. Uso dos prazeres $e$ Cuidado de si nos oferecem a imagem completamente diferente de sujeitos livres. Parece haver ali uma importante modificação em seu próprio pensamento (Foucault, 2004b, p. 248).

Em outra entrevista, Foucault (2004c, p. 253) esclarece o comentário de François Ewald:

Tentei destacar três grandes tipos de problemas: o da verdade, o do poder e o da conduta individual. Esses três grandes domínios da experiência só podem ser entendidos uns em relação aos outros, e não podem ser compreendidos uns sem os outros. O que me incomodou nos livros precedentes foi o fato de eu ter considerado as duas primeiras experiências sem levar em conta a terceira.

\section{Liberdade e governo}

Pesquisar as formas de subjetivação em sua historicidade, analisando-as como um domínio diferenciado do saber e do poder, embora a eles associado, acarreta algumas dificuldades teóricas. Como pensar o sujeito engendrando-se a si próprio sem retornar à noção de subjetividade livre, soberana, auto-fundante? Como compatibilizar essa idéia com o ponto de vista de que ser sujeito é estar assujeitado a um dispositivo? Em suma, qual o estatuto da liberdade nessa teorização?
Foucault (2004d) afirma que sempre desconfiou do tema da libertação, por entender que ele pressupõe a existência de uma experiência humana primordial, anterior e indiferente aos processos históricos, a qual se encontra alienada ou aprisionada por mecanismos repressivos. Para tal concepção, a libertação consiste no movimento de arrancar os poderosos tentáculos de poder, que mantêm constrangida a livre expressão da natureza humana. Em contrapartida, o interesse de Foucault se localiza nas práticas de liberdade intrínsecas às relações de poder.

De acordo com Foucault (1995b, p. 244), as relações entre poder e liberdade são de incitação recíproca: "no centro da relação de poder, 'provocando-a' incessantemente, encontra-se a recalcitrância do querer e a intransigência da liberdade". Nessa perspectiva, a liberdade é pré-condição da existência de relações de poder e seu suporte permanente, pois, sem a possibilidade de resistência, o que existe é a coerção absoluta e a impossibilidade de qualquer transformação. É porque o exercício do poder implica resistência, que as relações de poder constituem configurações estratégicas móveis, instáveis e reversíveis. Entretanto, Foucault (2004d, p. 266) reconhece a existência de " $[. .$.$] estados de dominação, nos quais as relações de$ poder, em vez de serem móveis e permitirem aos diferentes parceiros uma estratégia que os modifique, se encontram bloqueadas e cristalizadas". Nessas circunstâncias, em que as práticas de liberdade apresentam-se fortemente restringidas, fazem-se necessários vigorosos movimentos de libertação, que as tornem novamente potentes.

A partir dessas análises, é possível afirmar que é em um processo agonístico que a subjetivação se produz. É porque há forças no sentido do seu assujeitamento que a subjetividade resiste e toma a si própria como objeto de elaboração. Entretanto, nesse movimento não se funda a si mesma, nem descobre a verdade inalienável do seu ser, contrapondo-se às identidades impostas pelos dispositivos em que se insere. Nessas práticas de liberdade, é ainda em relação a critérios de verdade historicamente estabelecidos que o sujeito constitui-se:

[...] se agora me interesso de fato pela maneira com a qual o sujeito se constitui de uma maneira ativa, através das práticas de si, essas práticas não são, entretanto, alguma coisa que o próprio indivíduo invente. São esquemas que ele encontra em sua cultura e que lhe são propostos, sugeridos, impostos por sua cultura, sua sociedade e seu grupo social (Foucault, 2004d, p. 276).

Essa conceitualização implica pensar um dispositivo a partir das suas técnicas de governabilidade. Foucault (2004d, p. 286) conceitua governabilidade como o "conjunto das práticas pelas quais é possível constituir, definir, organizar, instrumentalizar as estratégias que os indivíduos, em sua liberdade, podem ter uns em relação aos 
outros". Nesse sentido, governar é dirigir condutas - próprias e/ou de outros -, em jogos estratégicos de poder e liberdade. Foucault (2004b) sugere que a constituição da experiência de $\mathrm{si}$ - a subjetivação - se dá no ponto de articulação entre as técnicas de governo dos outros e as técnicas de governo de si, podendo a análise privilegiar um ou outro desses conjuntos estratégicos. Em dispositivos nos quais as práticas de liberdade são mais estritas, o governo dos outros tende a ser o elemento forte da investigação. Por outro lado, naqueles em que as correlações de força são mais instáveis, é o governo de si o foco mais importante da pesquisa. Entretanto, Foucault (1999a) afirma ter encontrado dificuldades para investigar as técnicas de governo de si, pelo fato de tais práticas ainda não terem sido isoladas e construídas como objeto de análise e por ser difícil distingui-las em nossas experiências espontâneas.

Foucault (1997b, p. 109) denomina técnicas de si “[...] os procedimentos, que, sem dúvida, existem em toda civilização, pressupostos ou prescritos aos indivíduos para fixar sua identidade, mantê-la ou transformá-la em função de determinados fins, e isso graças a relações de domínio de si sobre si ou de conhecimento de si por si". Dito de outra forma, essas técnicas consistem em conjuntos de práticas, por meio das quais um sujeito toma a si próprio como objeto de saber e de poder, visando aceder a certas modalidades de relação consigo, que lhe parecem mais aperfeiçoadas. É nesse sentido que Foucault (1999a, p. 445) as define como técnicas

[...] que permitem aos indivíduos efetuar, sozinhos ou com a ajuda de outros, algumas operações sobre o seu corpo e a sua alma, os seus pensamentos, as suas condutas e o seu modo de ser, assim como se transformar, a fim de alcançar um certo estado de felicidade, de força, de sabedoria, de perfeição, ou de imortalidade.

No entanto, a condição histórica da organização dessas técnicas de governo de si e dos outros é que a experiência que um sujeito faz de si próprio e do mundo em que vive tenha se tornado problemática. Tal problematização pressupõe que um domínio de práticas constitutivas dessa experiência tenha se tornado incerto, tenha perdido a sua familiaridade, tenha suscitado dificuldades (Foucault, 2004e). São as fraturas de um dispositivo, decorrentes do processo de reacomodação nas correlações de forças que lhe são imanentes, que incitam o pensamento ${ }^{4} \mathrm{e}$ induzem à formação de técnicas de governabilidade em um determinado campo da experiência.

Nesse sentido, Foucault, em Vigiar e punir, não escreve uma história da instituição penitenciária, mas faz a genealogia de uma ruptura na racionalidade punitiva - no caso, a problematização da prática do suplício e o estabelecimento de uma nova forma de governo dos que infringem a lei: a privação da liberdade -, enfocando um con- junto de mutações em curso nas sociedades européias: fundamentalmente, a organização das instituições disciplinares. Entretanto, se em Vigiar e punir é sobre o governo dos outros que recai a ênfase da investigação - a constituição da subjetividade delinqüente é analisada em termos de assujeitamento -, em $O$ uso dos prazeres e $O$ cuidado de si o enfoque privilegiado é o das técnicas de si.

Nessas obras, Foucault descreve as circunstâncias históricas ${ }^{5}$ em que gregos e latinos da Antigüidade clássica e tardia elegem os prazeres como alvo de uma intensa problematização moral, da qual decorre a constituição de si próprio como sujeito ético - o governo de si - não por força de um constrangimento, mas como uma prática de liberdade. Em uma e em outra investigação, analisar " [....] as problematizações através das quais o ser se dá como podendo e devendo ser pensado, e as práticas a partir das quais essas problematizações se formam" (Foucault, 2001, p. 15) é condição para a compreensão da organização das técnicas de governabilidade pesquisadas.

\section{Ética e subjetivação}

Tomar como fio condutor da análise das formas de subjetivação as problematizações, por meio das quais um sujeito oferece ao pensamento a experiência que faz de si próprio e do mundo em que vive, e as práticas de si, mediante as quais essa subjetividade elabora a si própria, em um exercício de liberdade e em uma relação com a verdade, implica inserir-se em um domínio que Foucault denomina ética. ${ }^{6}$ Por esse motivo, as pesquisas genealógicas dos modos de subjetivação elegem a ética como a sua via privilegiada de investigação (Foucault, 1995d).

Foucault conceitua ética, situando-a em relação ao campo mais geral da moral. Nessa perspectiva, postula que este último conceito possui três sentidos principais: aquele que designa um código moral determinado, o que se refere à moralidade efetiva dos comportamentos e outro que diz respeito ao que é específico à ética. Por código moral, Foucault (2001, p. 26) entende "[...] um conjunto de valores e regras de ação propostas aos indivíduos e aos grupos por intermédio de aparelhos prescritivos diversos, como podem ser a família, as instituições educativas, as Igrejas, etc". Esse conjunto de prescrições pode se apresentar como uma doutrina coerente, unificada e explícita, ou ser assistemático, disperso e transmitido de uma forma difusa. Por sua vez, a moralidade dos comportamentos refere-se às condutas efetivamente adotadas pelos sujeitos, frente às normas que lhes são propostas. Ela aponta para a variação existente entre o código e as condutas, permitindo inferir o nível de submissão e obediência, ou de resistência e transgressão em relação às prescrições morais.

Por ética, Foucault (2001, p. 27) compreende "[...] a maneira pela qual é necessário 'conduzir-se' - isto é, a maneira pela qual se deve constituir a si mesmo como sujeito moral, agindo em referência aos elementos prescritivos 
que constituem o código". A ética, enquanto elaboração de si próprio como sujeito moral, é analisada por Foucault em quatro aspectos:

- Ontologia: consiste na determinação da substância ética, na eleição da parte de si sobre a qual incide a prática moral.

- Deontologia: refere-se ao modo como o sujeito vinculase ao dever de pôr a regra moral em prática.

- Ascética: concerne às formas de realizar o trabalho ético, operado sobre si próprio visando à transformação de si em sujeito moral.

- Teleologia: é o alvo, a finalidade da ação ética; o sujeito moral em sua forma acabada. ${ }^{7}$

A partir dessas formulações, depreende-se que a conduta moral oscila entre dois pólos indissociáveis, porém relativamente autônomos: o do código e o da ética. Nesse sentido, em algumas moralidades - no sentido amplo da palavra - a ênfase incide sobre a codificação da conduta, implicando formas de subjetivação quase jurídicas, dotadas de estreita margem de liberdade. Em contrapartida, há moralidades que se orientam para a ética e privilegiam as modalidades de relação consigo, isto é, os procedimentos por meio dos quais um sujeito visa conhecer-se e transformar-se. Nessas circunstâncias, as práticas de liberdade são muito mais disseminadas e os modos de subjetivação, mais diversificados. Entretanto, tanto em uma moral organizada como código, quanto naquelas voltadas para a ética, as práticas de si consistem no fulcro do processo de constituição das subjetividades:

Não acredito que haja moral sem um certo número de práticas de si. É possível que essas práticas de si estejam associadas a estruturas de código numerosas, sistemáticas e coercitivas. É até possível que elas quase se apaguem em benefício desse conjunto de regras que então aparecem como o essencial de uma moral. Mas também é possível que constituam o foco mais importante e mais ativo da moral e que seja em torno delas que se desenvolva a reflexão. As práticas de si assumem assim a forma de uma arte de si, relativamente independente de uma legislação moral (Foucault, 2004b, p. 244).

Uma outra decorrência dessas distinções conceituais é que se faz necessário especificar em que nível opera uma história da moral: se no nível do código, da moralidade, ou da ética. Uma história dos códigos ocupa-se dos sistemas de regras e valores de uma determinada sociedade e das instituições encarregadas de torná-los efetivos. Uma história das moralidades estuda as ações dos grupos e indivíduos, avaliando em que medida as suas condutas aproximam-se ou afastam-se das normas prescritas. Uma história (genealógica) da ética debruça-se sobre as formas singulares, por meio das quais os sujeitos problematizam a experiência que têm de si próprios, e sobre as práticas de si, mediante as quais esses sujeitos esforçam-se por elaborarem-se de uma forma que lhes pareça mais aceitável. ${ }^{8}$

\section{Cartografar um dispositivo}

Portanto, investigar a sexualidade como experiência, isto é, nos três eixos que a constituem - os domínios de saber que a ela se referem, os sistemas de poder que regulam a sua prática e as formas de subjetivação, mediante as quais nos elaboramos como sujeitos desejantes (Foucault, 2001) -, implica pensar a constituição de um sujeito de um modo diferente. Se, nas pesquisas foucaultianas anteriores, um sujeito aparece como resultado de uma operação de assujeitamento a um dispositivo, nessa nova perspectiva a subjetivação é concebida como um processo do qual um sujeito participa ativamente. Por meio do conceito de experiência, Foucault coloca os processos de subjetivação no mesmo nível dos que concernem ao saber e ao poder, em um tipo de entrelaçamento diverso daquele em que a subjetividade aparece apenas como uma derivada das relações de saber/poder.

Essa nova conceitualização requer que se pense um dispositivo como um conjunto heterogêneo de práticas de saber, de poder e de subjetivação. Em O que é um dispositivo?, Deleuze constrói essa articulação. Deleuze postula que um dispositivo é um conjunto multilinear, composto de linhas de distintas naturezas, as quais percorrem esse dispositivo em todos os sentidos, delineando processos diversos, os quais se encontram em permanente desequilíbrio. Essas linhas são vetores ou tensores, que podem endurecer, sedimentando um dispositivo (linhas de estratificação), mas que também podem quebrar, produzindo variações de direção, ou bifurcar, engendrando derivações, isto é, podem configurar-se como linhas de atualização, por meio das quais se operam as transformações de um dispositivo. Deleuze assinala que Foucault cartografa um dispositivo a partir de três grandes feixes de linhas. Esses feixes não são homogêneos, nem possuem contornos definidos, mas consistem em sistemas de variáveis, que se desdobram umas das outras: o saber, o poder e a subjetivação.

Deleuze observa que as linhas do saber comportam curvas de visibilidade e de enunciação. E isso por que um dispositivo é uma máquina de fazer ver e de fazer falar. As linhas de visibilidade instauram feixes de luz, que formam figuras variáveis: "cada dispositivo tem o seu regime de luz, uma maneira como cai a luz, se esbate e se propaga, distribuindo o visível e o invisível, fazendo com que nasça ou desapareça o objeto que sem ela não existe" (Deleuze, 1996, p. 84). Portanto, um dispositivo pode ser concebido como uma máquina ótica construída em condições históricas específicas, a qual estabelece áreas de visibilidade e de invisibilidade e engendra, simultaneamente, um sujeito que vê e um objeto a ser visto. Porém, um dispositivo consiste, também, em uma máquina enun- 
ciativa singular, a qual determina o regime de dispersão dos enunciados em um conjunto de práticas discursivas, indicando as diversas posições do sujeito e do objeto no discurso, as modalidades de enunciação, as definições conceituais, as escolhas estratégicas, etc (Foucault, 2000).

Um dispositivo também comporta linhas de força que, invisíveis e indizíveis, articulam o ver e o dizer, definindo as condições de possibilidade do saber. São linhas que tangenciam as curvas de visibilidade e de enunciação, indo de um ponto a outro dessas curvas, em um vaivém incessante, cruzando-as, trespassando-as, dobrando-as umas sobre as outras, tecendo a urdidura do saber. É a dimensão do poder, que Foucault analisa em termos de tecnologias específicas - poder pastoral, poder soberano, poder disciplinar, bio-poder, etc -, por meio da investigação das condições históricas de sua organização.

Por fim, um dispositivo possui linhas de subjetivação. Deleuze sugere que Foucault puxou mais esse fio ao perceber que a dimensão do poder estava encerrando o mapa dos dispositivos em linhas de força intransponíveis, que impõem contornos definitivos. A subjetivação consiste, precisamente, na resistência à ação de tais forças, no ato de recurvá-las, de voltá-las sobre si próprias, constituindo uma dimensão que escapa tanto aos saberes, quanto aos poderes estabelecidos (embora possa, a todo o momento, ser por eles recapturada): o si próprio. Nessa perspectiva, a subjetivação aparece como uma linha de fuga, que transpõe o limiar de um dispositivo, que lhe abre uma fissura: "podemos perguntar se as linhas de subjetivação não são o extremo limite de um dispositivo, e se não esboçam elas a passagem de um dispositivo a um outro: neste sentido, elas predispõem as 'linhas de fraturas"' (Deleuze, 1996, p. 86).

Em Foucault, Deleuze desenvolve essas suas análises a respeito da subjetivação. Deleuze atribui o silêncio de Foucault, após a publicação de $A$ vontade de saber, ao fato de sua teorização encontrar-se enredada nas relações de poder. O próprio Foucault (2003, p. 208) teria expressado essa inquietação:

\section{Alguém me dirá: isto é bem próprio de você, sempre a mesma incapacidade de ultrapassar a linha, de passar para o outro lado, de escutar e fazer ouvir a linguagem que vem de outro lugar ou de baixo; sem- pre a mesma escolha, do lado do poder, do que ele diz ou do que ele faz dizer.}

No entanto, Deleuze assinala que a analítica foucaultiana do poder, tal como essa é realizada em $A$ vontade de saber, aponta para uma "[...] multiplicidade de correlações de força imanentes ao domínio onde se exercem e constitutivas de sua organização" (Foucault, 1997a, p. 88). Embora estas correlações de forças possam constituir estados de dominação relativamente estáveis - dos quais é possível traçar o diagrama -, a sua configuração é perma- nentemente desestabilizada e subvertida pelos feixes de forças sobre os quais se exerce esse poder, pelos efeitos de resistência que este exercício induz. Estas resistências - elas próprias, poder -, por mais minúsculas, medíocres e infames que sejam, são o que torna possível transpor as linhas diagramatizadas do poder - ainda que por um breve instante - e fazer fulgurar o novo: "o ponto mais intenso das vidas, aquele em que se concentra sua energia, é bem ali onde elas se chocam com o poder, se debatem com ele, tentam utilizar suas forças ou escapar de suas armadilhas" (Foucault, 2003, p. 208).

É nesse choque com as linhas de força hegemônicas que a subjetivação produz-se como uma prega, como uma dobradura dos regimes de saber e poder que nos atravessam: "é como se as relações do lado de fora se dobrassem, se curvassem para formar um forro e deixar surgir uma relação consigo, constituir um lado de dentro que se escava e desenvolve segundo uma dimensão própria" (Deleuze, 2005, p. 107). Nesse movimento de invaginação de uma experiência histórica singular, a relação consigo elabora-se de forma coextensiva à relação com os outros, sem que se constitua em uma interioridade. Trata-se da outra face de uma pura exterioridade, que é a superfície imanente onde as forças em jogo têm a possibilidade de afetarem-se não apenas umas às outras, mas, também, a si próprias. Deleuze (id, p. 108) expressa esse jogo de forças, do qual emerge o si próprio, da seguinte forma:

O que pertence ao lado de fora é a força, porque em sua essência ela é relação com outras forças: em si mesma, ela é inseparável do poder de afetar outras forças (espontaneidade) e de ser afetada por outras (receptividade). Mas, o que decorre, então, é uma relação da força consigo, um poder de se afetar a si mesmo, um afeto de si por si.

De acordo com essa conceitualização, o que a dobra da subjetivação instaura é uma modalidade de relação consigo, irredutível aos saberes e poderes dos quais deriva, visto que se erige insurgindo-se contra as formas de subjetividade que nos são propostas e impostas pelos dispositivos em que nos inserimos. Entretanto, esse novo domínio - o si próprio - é continuamente penetrado, recuperado e reintegrado em novos saberes e poderes, que o recodificam e rediagramatizam, de modo a assujeitar (ao outro: submissão; a si próprio: identidade) a subjetivação. Deleuze aponta que é próprio à subjetivação resistir à sujeição e que ela não deixa de relançar a relação consigo redobrandose, desdobrando-se, metamorfoseando-se. Nesse sentido, cartografar um dispositivo consiste em instalar-se sobre as suas linhas e delinear os processos mediante os quais se define o que somos (linhas de estratificação) e estamos deixando de ser e o que somos em devir (linhas de atualização), isto é, aquilo em que estamos nos tornando (Deleuze, 1996). 


\section{Notas}

1 Foucault (2004a, p. 237) define universais antropológicos como "tudo o que nos é proposto em nosso saber, como sendo de validade universal, quanto à natureza humana ou às categorias que se podem aplicar ao sujeito".

2 Foucault (1995b, p. 235) assinala que "há dois significados para a palavra sujeito: sujeito a alguém pelo controle e dependência, e preso à sua própria identidade por uma consciência ou autoconhecimento. Ambos sugerem uma forma de poder que subjuga e torna sujeito a".

3 Como afirma Foucault (1997a), essas estratégias são, ao mesmo tempo, intencionais e a-subjetivas.

4 De acordo com Foucault (2004e, pp. 231-232), "o pensamento não é o que se presentifica em uma conduta e lhe dá um sentido; é, sobretudo, aquilo que permite tomar uma distância em relação a essa maneira de fazer ou de reagir, e tomá-la como objeto de pensamento e interrogá-la sobre seu sentido, suas condições e seus fins. O pensamento é liberdade em relação àquilo que se faz, o movimento pelo qual dele nos separamos, constituímo-lo como objeto e pensamo-lo como problema".

5 A organização da democracia, entre os gregos da Era Clássica (séculos V e IV a.C.), associa-se a uma problematização do uso dos prazeres, que culmina na formulação de um princípio ético, de acordo com o qual aquele que governa a cidade e a sua casa deve ser capaz de domínio de si (Foucault, 2001). Por outro lado, o declínio das cidades-Estado e a constituição das monarquias helenísticas -e, em seguida, do Império Romano -, bem como algumas modificações na instituição do casamento, as quais fortalecem a autoridade do Estado sobre a família, implicam o enfraquecimento do poder público dos homens livres e redirecionam a problematização dos prazeres no sentido do cuidado de si (Foucault, 1999b).

6 Sobre as relações entre ética e liberdade, Foucault (2004d, p. 267) afirma o seguinte: “(...) o que é a ética senão a prática da liberdade, a prática refletida da liberdade? (...) A liberdade é a condição ontológica da ética. Mas a ética é a forma refletida assumida pela liberdade".

7 Esses elementos, em que se desdobra a ética, conferem unidade à conduta moral.É em um mesmo movimento que "[...] o indivíduo circunscreve a parte dele mesmo que constitui o objeto dessa prática moral, define sua posição em relação ao preceito que respeita, estabelece para si um certo modo de ser que valerá como realização moral dele mesmo; e, para tal, age sobre si mesmo, procura conhecer-se, controla-se, põe-se à prova, aperfeiçoa-se, transforma-se" (Foucault, 2001, p. 28).

8 Referindo-se especificamente à sua genealogia do sujeito do desejo - mas em termos que me parecem apropriados para definir a genealogia da ética, como método que orientou essa investigação -, Foucault (2001, p. 16) afirma que ela “[...] se encontra no ponto de intersecção entre uma arqueologia das problematizações e uma genealogia das práticas de si”.

\section{Referências}

Ariès, P. (1981). História social da criança e da família (D. Flaksman, Trad.). Rio de Janeiro: LTC.

Corazza, S. (2000). História da infância sem fim. Ijuí: UNIJUÍ.

Deleuze, G. (2005). Foucault (C. Martins, Trad.). São Paulo: Brasiliense.

Deleuze, G. (1996). O que é um dispositivo? In: G. Deleuze, O mistério de Ariana (pp. 83-96). Lisboa: Vega.

Foucault, M. (1987). Vigiar e punir: nascimento da prisão (L. Vassalo, Trad.). Petrópolis, RJ: Vozes.
Foucault, M. (1995a). Verdade e poder. In: M. Foucault Microfísica do poder (pp. 1-14). Rio de Janeiro: Graal.

Foucault, M. (1995b). O sujeito e o poder. In: P. Rabinow, \& H. Dreyfus (Eds.), Michel Foucault, uma trajetória filosófica: para além do estruturalismo e da hermenêutica (pp. 231-249). Rio de Janeiro: Forense Universitária.

Foucault, M. (1995c). Sobre a história da sexualidade. In: M. Foucault, Microfísica do poder (pp. 243-276). Rio de Janeiro: Graal.

Foucault, M. (1995d). Sobre a genealogia da ética: uma revisão do trabalho. In: P. Rabinow, \& H. Dreyfus (Eds.), Michel Foucault, uma trajetória filosófica: para além do estruturalismo e da hermenêutica (pp. 253-278). Rio de Janeiro: Forense Universitária.

Foucault, M. (1997a). História da sexualidade I: a vontade de saber (M. Albuquerque \& Albuquerque, Trads.). Rio de Janeiro: Graal.

Foucault, M. (1997b). Subjetividade e verdade. In: M. Foucault, $R e$ sumo dos cursos do Collège de France (pp. 107-116). Rio de Janeiro: Jorge Zahar.

Foucault, M. (1999a). Las técnicas de sí. In: Á. Gabilondo (Ed.), Estética, ética y hermenéutica (pp. 443-474). Barcelona: Paidós.

Foucault, M. (1999b). História da sexualidade III: o cuidado de si (M. Albuquerque, Trad.). Rio de Janeiro: Graal.

Foucault, M. (2000). A arqueologia do saber (L. Neves, Trad.). Rio de Janeiro: Forense Universitária.

Foucault, M. (2001). História da sexualidade II: o uso dos prazeres (M. Albuquerque, Trad.). Rio de Janeiro: Graal.

Foucault, M. (2002). As palavras e as coisas: uma arqueologia das ciências humanas (S. Muchail, Trad.). São Paulo: Martins Fontes.

Foucault, M. (2003). A vida dos homens infames. In: M. B. Motta (Ed.), Estratégia, poder-saber (pp. 203-222). Rio de Janeiro: Forense Universitária.

Foucault, M. (2004a). Foucault. In: M. B. Motta (Ed.), Ética, sexualidade, política (pp. 234-239). Rio de Janeiro: Forense Universitária.

Foucault, M. (2004b). O cuidado com a verdade. In: M. B. Motta(Ed.), Ética, sexualidade, política (pp. 240-251). Rio de Janeiro: Forense Universitária.

Foucault, M. (2004c). O retorno da moral. In: M. B. Motta (Ed.), Ética, sexualidade, política (pp. 252-263). Rio de Janeiro: Forense Universitária.

Foucault, M. (2004d). A ética do cuidado de si como prática de liberdade. In: M. B. Motta (Ed.), Ética, sexualidade, política (pp. 264-287). Rio de Janeiro: Forense Universitária.

Foucault, M. (2004e). Polêmica, política e problematizações. In: M. B. Motta (Ed.), Ética, sexualidade, política (pp. 225-233). Rio de Janeiro: Forense Universitária.

Amadeu de Oliveira Weinmann. Psicólogo, historiador, especialista em Clínica Psicanalítica e doutorando em Educação (PPGEDU/UFRGS). Endereço: Av. Montenegro, 186/602 - POA/RS - CEP: 90.460-160 Fone: (51) 3332.5930. weinmann.amadeu@gmail.com

\section{Dispositivo: um solo para a subjetivação}

Amadeu de Oliveira Weinmann

Recebido: 06/04/2006

$1^{\text {a Revisão: } 29 / 04 / 2006}$

Aceite final: 22/05/2006 